\title{
Opposite associations of household income with adolescent body mass index according to migrant status: Hong Kong's “Children of 1997" birth cohort
}

\section{Citation}

Kwok, Man Ki, C. Mary Schooling, S. V. Subramanian, Gabriel M. Leung, and Ichiro Kawachi. 2018. "Opposite Associations of Household Income with Adolescent Body Mass Index According to Migrant Status: Hong Kong's 'Children of 1997' Birth Cohort." International Journal of Obesity 42 (6) (June): 1221-1229. doi:10.1038/s41366-018-0118-x.

\section{Published Version}

doi:10.1038/s41366-018-0118-x

\section{Permanent link}

http://nrs.harvard.edu/urn-3:HUL.InstRepos:37228290

\section{Terms of Use}

This article was downloaded from Harvard University's DASH repository, and is made available under the terms and conditions applicable to Other Posted Material, as set forth at http:// nrs.harvard.edu/urn-3:HUL.InstRepos:dash.current.terms-of-use\#LAA

\section{Share Your Story}

The Harvard community has made this article openly available.

Please share how this access benefits you. Submit a story.

Accessibility 
OPPOSITE ASSOCIATIONS OF HOUSEHOLD INCOME WITH ADOLESCENT

\section{BODY MASS INDEX ACCORDING TO MIGRANT STATUS: HONG KONG'S}

\section{“CHILDREN OF 1997” BIRTH COHORT}

Man Ki Kwok, C Mary Schooling, S V Subramanian, Gabriel M Leung, Ichiro Kawachi

Author affiliations: School of Public Health, Li Ka Shing Faculty of Medicine, The University of Hong Kong, Hong Kong Special Administrative Region, China (Man Ki Kwok, Gabriel M

Leung, C Mary Schooling); Department of Social and Behavioral Sciences, Harvard T.H.

Chan School of Public Health, Boston, Massachusetts, United States (Ichiro Kawachi, S V

Subramanian); and City University of New York Graduate School of Public Health and Health Policy, New York, United States (C Mary Schooling).

Correspondence to Dr. C Mary Schooling, School of Public Health, Li Ka Shing Faculty of Medicine, The University of Hong Kong; 1/F, Patrick Manson Building (North Wing), 7

Sassoon Road, Hong Kong Special Administrative Region, China (e-mail: cms1@ @ku.hk; telephone: (852) 3917 6732; fax: (852) 3520 1945).

Abbreviations: BMI - body mass index, CI - confidence interval, IPW/MI - inverse probability weighting with multiple imputation, z-score - standard deviation score

Word count: 270 (abstract) and 3,504 (manuscript) 
ABSTRACT

Background/Objectives: In economically developed settings, household income is usually inversely associated with child and adolescent adiposity, but this association may not extend to migrants. Hong Kong is a unique developed setting to study how household income and adolescent adiposity vary by migrant status given many Hong Kong-born Chinese children were born to parents who migrated from neighbouring provinces of Mainland China.

Subjects/Methods: We examined differences between the associations of absolute household income versus relative household income on adolescent body mass index (BMI) z-score or overweight (including obesity) status using a linear or logistic model in a Chinese birth cohort ( $n=5,613,68 \%$ follow-up). We focused on whether the associations differed by mother's or father's migrant status (birthplace).

Results: No association was found between absolute household income and BMI z-score among adolescents with either native or migrant mothers. However, the association of relative household income with BMI z-score varied by mother's migrant status ( $P$-values for interaction $<0.0005)$. In adolescents of native born mothers, greater relative household income deprivation was associated with higher BMI z-score (0.03 z-score per USD 128 difference in Yitzhaki index, $95 \%$ confidence interval (CI) 0.01 to 0.05 ). However, in adolescents of migrant mothers, greater relative household income deprivation was associated with lower BMI z-score $(-0.05,95 \%$ CI -0.09 to -0.01$)$. Similar association of relative household income with overweight (including obesity) status was found in adolescents of native born mothers but not in adolescents of migrant mothers.

Conclusions: Relative income (mediated by social comparisons with others in society) appears to be relevant to adolescent adiposity, but the association depends on the interplay between individual characteristics (migrant background) and societal context.

Keywords: adolescent; absolute income; relative income; body mass index; socioeconomic position 


\section{INTRODUCTION}

The nutrition transition is associated with a reversal in the social patterning of child and adolescent adiposity with economic development. ${ }^{1}$ In economically less developed countries, lower household income is associated with under-nutrition, while higher incomes are associated with greater prevalence of child and adolescent adiposity. ${ }^{2,3}$ This pattern becomes more mixed with a rise in living standards. ${ }^{4,5}$ In economically developed countries, such as the United Kingdom, a mixed social pattern prior to the late $1980 \mathrm{~s}^{2}$ has shifted to a largely inverse association of household income with child and adolescent adiposity since the $1990 \mathrm{~s}^{6}$ However, even within affluent countries, such as the United States, a positive association between income and adiposity can be still observed in minority ethnic groups ${ }^{7}$ and among immigrants of lower socioeconomic position. ${ }^{8}$

Decomposing income into absolute (income per se) or relative (social comparisons of income) at household level may provide insights into how income affects adiposity. ${ }^{9}$ Absolute household income confers the ability to purchase and access material resources, such that poor households in any neighbourhood are likely affected. Food expenditure composes a larger income share in poor households ${ }^{10}$ and lower-priced calorie-dense, nutrient-low food that is more filling encourages unhealthy diet in low-income children. ${ }^{11}$ They also participate less organized physical activity ${ }^{12}$ and underutilize preventive health service. ${ }^{13}$ Relative household income refers to a lack of resources compared with others. ${ }^{14}$ A relatively poor household may not be deprived in any absolute sense (e.g. lacking the ability to afford food, shelter, clothing), but they may be deprived in the sense of not being able to participate fully in the norms and lifestyles set by the middle class. For example, an adolescent growing up in a relatively poor household may own a pair of shoes, but they might not be the "right" type to participate in certain sports activities, such as basketball. Relative deprivation can also increase stress and frustration through upward social comparisons. ${ }^{15}$ Psychosocial stress may in turn increase 
appetite, ${ }^{16}$ encourage stress-coping behaviours like overeating, or trigger anxiety and depression, resulting in adiposity. ${ }^{17}$

Taken together, the inconsistent associations of household income with child and adolescent adiposity across countries highlights the importance of family experience of socioeconomic conditions in child and adolescent adiposity. Economic growth does not benefit all families equally. With varying levels of economic development between countries (developed or developing), families with higher income have more material and symbolic resources (conferred by absolute and relative income) to keep their child's weight within cultural and societal norms. As such, children from higher income families might have lower weight if adiposity is a concern, or higher weight if undernutrition is a concern. Given adiposity is shaped by socio-cultural norms, children from migrant families might be more or less prone to adiposity than those from native families even within countries and income levels depending on the norms in their countries of origin. Hence, the role of absolute and relative income in child and adolescent adiposity may vary by level of economic development and migrant status.

To date, the relative contribution of absolute and relative income to adolescent adiposity has not been systematically studied, but is important to distinguish for the design of interventions. ${ }^{18}$ If only absolute income matters, increasing income by the same amount for every household (e.g. providing universal basic income) would be relevant. If only relative income matters, reducing income inequality or promoting intragenerational relative income mobility would be more relevant. If both absolute and relative income matter, then increasing income, reducing income inequality and promoting intragenerational relative income mobility would all be relevant to tackling adolescent adiposity. Relative income may be particularly relevant in economically developed settings with widening gaps in income. Hong Kong society is a unique "natural laboratory" to disentangle the contributions of absolute and 
relative income to adolescent adiposity. The Hong Kong population was mainly formed in the mid-20th century by an influx of young workers from neighbouring provinces such as Guangdong after the World War II. ${ }^{19}$ Hence, Hong Kong-born Chinese children are mainly the second- (native born children born to at least one migrant parent) or third-generation (native born and both parents native born) migrants. Many second- or third-generation Hong Kongborn Chinese children have enjoyed a standard of living that is comparable to developed Western countries for their entire lives. By contrast, their parents may have experienced very different economic circumstances; migrant parents were born into and grew up in very limited conditions in Mainland China. Second generation migrant Chinese families might be

"relatively deprived" in Hong Kong, but their economic circumstances might still be an improvement compared to their previous standard of living. Therefore, the psychological burden (and health impact) of relative deprivation might be quite different for native-born compared to migrant families. We therefore examined the associations of absolute or relative household income with adolescent adiposity, and whether the associations varied by parental migrant status using a Chinese birth cohort in Hong Kong.

\section{MATERIALS AND METHODS}

\section{Data Source}

Hong Kong's "Children of 1997” birth cohort is a population representative Chinese birth cohort $(n=8,327)$ that covered 88.0\% of all births in Hong Kong from April 1, 1997 to May 31, 1997, described in detail elsewhere. ${ }^{20}$ The study was initially established to investigate the effect of second-hand smoke exposure on infant health. Families were recruited at the first postnatal visit to any of the 49 Maternal and Child Health Centers in Hong Kong, which parents of all newborns are strongly encouraged to attend for free vaccinations and well-baby checks. Characteristics obtained using a self-administered questionnaire in Chinese at recruitment and subsequent routine visits include maternal and birth characteristics and 
parental education. Monthly household income and household size was also reported. Passive follow-up via record linkage was instituted in 2005 to obtain routinely collected information including annual measurements of weight and height (grade 1 (age 6-7 years) onwards) from the Student Health Service, Department of Health, which provides free annual check-ups for all school students ( $n=7,809,94 \%$ successful matching). At the Student Health Service, height without shoes was measured by stadiometer to the nearest 0.1 centimetre and weight without shoes and outer clothing was measured by digital scale to the nearest 0.1 kilogram. Parental migrant status was based on a postal survey (Survey I) in 2008-2009 and a postal survey (Survey III) with telephone follow-up in 2011-2012, supplemented by parental residency status based on parental age, year of parental migration to Hong Kong and residency eligibility (mothers or fathers who were not residents of Hong Kong, or who were residents but were not born in Hong Kong or who reported migration to Hong Kong were classified as migrants) from the baseline questionnaire in 1997.

\section{Exposures}

\section{Absolute income}

Absolute household income was equivalized by dividing the monthly household income by the square root of household size, ${ }^{21}$ consistent with a previous study of this birth cohort. ${ }^{22}$

\section{Relative income}

Relative household income was assessed by two measures - income deprivation and income rank. Relative household income deprivation was measured by the Yitzhaki index ${ }^{23}$ which is the average difference in equivalized household income per head between the index household and every other household with a higher household income in the comparison group (in the birth cohort). Relative household income rank is the income distribution percentile divided by 100, based on equivalized household income per head, and ranges from 0 (for the child with 
the lowest income) to 1 (for the child with the highest income) ${ }^{24}$ As such relative household income deprivation includes rank and difference in income while relative household income rank only considers ranking. Distinguishing between income deprivation and rank has different implications for intervention. ${ }^{18}$ If only deprivation matters, increasing household income would be relevant to adolescent adiposity, whereas if only rank matters, reducing intragenerational relative income inequality would be more relevant. If both deprivation and rank matter, increasing household income, reducing income inequality and promoting intragenerational relative income mobility would all be relevant to adolescent adiposity.

Outcomes

We considered age- and sex-specific BMI z-score (standard deviation) at age 13 years (using the closest measurement at $12-<15$ years) relative to the 2007 World Health Organization growth references for 5-19 years. ${ }^{25} \mathrm{We}$ also defined adolescent overweight (including obesity) as a BMI for age and sex corresponding to an adult BMI of $\geq 25 \mathrm{~kg} / \mathrm{m}^{2}$ using the International Obesity Task Force cut-offs. ${ }^{26}$ Due to the relatively small number of obese adolescents $(n=$ 215; 3.8\%), overweight adolescents here included those who were obese.

Statistical analysis

We examined the associations of absolute or relative household income with BMI z-scores and overweight (including obesity) using a linear or logistic model. We assessed whether the associations varied by mother's migrant status or father's migrant status and whether the associations for relative household income varied by absolute household income from the heterogeneity of effect across strata and the significance of interaction terms. ${ }^{27}$ Since people tend to compare themselves to those with similar characteristics, as a sensitivity analysis, we examined the association of relative household income (deprivation or rank) defined by different comparison groups: residential neighbourhood (tertiary planning units, which 
represent clustered geographical units created for town planning purpose in Hong Kong), mother's and father's migrant status, and parental education.

Since absolute income, relative income deprivation and relative income rank represent different aspects of income and may have independent roles in adolescent adiposity (BMI zscore or overweight (including obesity) status), we present five models. First, Model 1 gives the unadjusted association of each of the three income measures (absolute household income, relative household income deprivation or relative household income rank) with each of the two measures of adolescent adiposity. Second, to distinguish the independent contribution of absolute income or relative income, Model 2 gives the mutually adjusted associations of both absolute household income and relative household income deprivation with both measures of adolescent adiposity, while Model 3 gives the mutually adjusted associations of both absolute household income and relative household income rank with both measures of adolescent adiposity. We considered deprivation and rank separately because they represent correlated yet distinct aspects of relative income. Third, to identify whether the role of absolute or relative income was independent of education (another key socio-economic indicator) and other possible confounders, Model 4 and Model 5 are Model 2 and Model 3 additionally adjusted for mother's and father's age and migrant status, and highest parental education.

Complete information on BMI at 13 years and household income was available for $68 \%$. We used multiple imputation with inverse probability weighting (IPW/MI) to recover the entire sample. ${ }^{28}$ We first imputed any missing potential confounders (i.e. parent's age, migrant status and highest parental education), but not exposures (absolute or relative income) or outcomes (BMI z-score or overweight (including obesity) status), 20 times for respondents with income and BMI based on a flexible additive regression model with predictive mean matching ${ }^{29}$ incorporating data on the outcomes, exposures, and covariates (sex, birth order, mode of 
delivery, second-hand smoke exposure, infant residency, parents' age, parents' migrant status, highest parental education, highest parental occupation, housing and interaction terms between income measures and parents' migrant status as well as those between absolute and relative income measures). ${ }^{30} \mathrm{We}$ predicted the probability of exclusion due to missing income or BMI based on these covariates to generate the IPW. We combined the results from 20 imputed dataset adjusted for the IPW into single estimates with confidence intervals to allow variability between imputations. ${ }^{28} \mathrm{We}$ also performed an available case analysis for comparison.

Statistical analyses were performed using Stata version 12.1 (Stata Corp, College station, Texas, USA) and R version 3.0.1 (R Development Core Team, Vienna, Austria).

\section{Ethics approval}

The study obtained ethical approval from the University of Hong Kong-Hospital Authority Hong Kong West Cluster Joint Institutional Review Board. Informed consent for the original survey and subsequent record linkage and surveys was obtained from the parents, next of kin, caretakers or guardians (informants).

\section{RESULTS}

Of the original 8,327 recruited, as of January 2016, 29 had permanently withdrawn. Of the remaining 8,298 adolescents, 2,685 were excluded because of missing income or BMI. Among the 5,613 included (68\% follow-up), 97\% had information on migrant status (mother $(\mathrm{n}=5,425)$ and father $(\mathrm{n}=5,456))$. At $\sim 13$ years mean BMI was $19.4 \mathrm{~kg} / \mathrm{m}^{2}$ in girls and 19.8 $\mathrm{kg} / \mathrm{m}^{2}$ in boys. One-fifth ( $15.6 \%$ of girls and $25.6 \%$ of boys) was overweight or obese. Parents with lower absolute household income were younger, less educated, and more often migrants from Mainland China or elsewhere (Table 1). 
The associations of absolute or relative household income with BMI z-score varied by mother's migrant status ( $P$-values for interaction $<0.0005)$, but not by father's migrant status $(P>0.46)$. The associations of relative household income with BMI z-score did not vary by absolute household income $(P>0.18)$.

Table 2 shows that when each income measure was considered separately, greater relative household income deprivation (Yitzhaki index) or lower relative household income rank was each associated with higher BMI z-score in adolescents of native born mothers, but with lower BMI z-score in adolescents with migrant mothers (Model 1). Absolute household income was not associated with adolescent BMI z-score. The associations remained unchanged when all income measures were considered together (Models 2 and 3). The estimates of relative household income for adolescents of native born mothers were attenuated, but those for adolescents of migrant mothers remained similar after adjustment for mother's and father's age, father's migrant status, and parental education (Models 4 and 5).

Considered separately, lower absolute household income, greater relative household income deprivation (Yitzhaki index), or lower relative household income rank was each associated with overweight (including obesity) in adolescents of native born mothers (Model 1).

However, only greater relative household income deprivation or lower relative household income rank was associated with overweight (including obesity) when all income measures were considered together (Models 2 and 3). The estimates of relative household income were attenuated by adjustment for mother's and father's age, father's migrant status, and parental education (Models 4 and 5). Income measures were not associated with overweight (including obesity) in adolescents of migrant mothers. 
The available case analysis (with listwise deletion of missing data) produced similar results (Appendix Table 1). In sensitivity analyses, the opposite associations of relative household income deprivation or rank defined by residential neighbourhood or parents' migrant status with adolescent BMI z-score according to mother's migrant status were similarly found (Appendix Table 2).

\section{DISCUSSION}

In a recent economically developed Chinese setting, relative household income (deprivation or rank) was associated with higher BMI z-score and overweight (including obesity) in adolescents of native born mothers, but with lower BMI z-score in adolescents with migrant mothers from Mainland China or elsewhere. Absolute household income was unrelated to adolescent adiposity. In adolescents of native born mothers, these associations were explained by adjustment for parental education but not in adolescents of migrant mothers.

Several limitations are noted. First, household income may have changed since birth. Relative household consumption or possessions or wealth could be a more direct measure, but is more difficult to measure and standardize. Second, relative household income deprivation or rank is inherently open to the uncertainty as regards the actual comparison group. We found similar associations using other comparison groups. Schoolmates or family members could be a more proximate comparison group, or native born adolescents with migrant mothers may compare themselves with migrant adolescents whose mothers did not migrate to Hong Kong, but we did not have such information. Finally, differential follow-up of BMI by household income and parental migrant status could bias the results, which is unlikely given health check-up at the Student Health Service is free-of-charge. Information on parental migrant status was incomplete. We used IPW/MI to minimize inclusion bias due to missingness or attrition without any reduction in sample size. An available case analysis produced similar results. 
287 Our finding of a lack of association between absolute income and adolescent BMI z-score differs from previous reports, mainly from North America. ${ }^{31-33}$ Hong Kong has highly accessible and affordable health care, free universal education, strong family ties and a social safety net, which might buffer the effect of income disparities between households and neighborhoods. Extensive, affordable public transport also facilitates common usage of societal infrastructure across districts.

To our knowledge, this is the first study distinguishing the role of absolute and relative household income in adolescent adiposity. As in developed countries, ${ }^{6}$ higher absolute household income was associated with overweight (including obesity) in adolescents of native born mothers. However, the association became null after adjusting for other income measures, and was not observed in adolescents of migrant mothers, unlike the positive association in minorities ${ }^{7}$ and migrants. ${ }^{8}$ Conversely, relative household income (greater relative deprivation or lower relative rank) was associated with higher BMI z-score and overweight (including obesity) in adolescents of native born mothers, but with lower BMI z-score in adolescents of migrant mothers, with or without adjustment for absolute income, suggesting the underlying mechanism may extend beyond access to material resources. The associations were similar in both sexes as others have found. ${ }^{6}$ No clear differences by father's migrant status suggest specific attributes of mothers may be relevant to the social patterning of child adiposity.

Alternatively, adolescents are acutely aware of their social position. ${ }^{34}$ A sense of relative deprivation or lower social position may trigger psychosocial stress. ${ }^{15}$ The resultant hypothalamic-pituitary-adrenal axis upregulation ${ }^{16}$ could stimulate appetite, trigger stresscoping behaviours, or induce anxiety or depression, and thus promote child and adolescent adiposity. ${ }^{17}$ Nonetheless, food availability constrains the stress-induced overeating tendency. 
312 Food would be more available to adolescents from families with native born mothers, which

313 generally have higher income than families with migrant mothers,${ }^{35}$ consistent with our

314 finding for absolute income only in adolescents of native born mothers. Equally possible,

315 adolescents with migrant mothers might be more resilient to stress than those with native born

316 mothers, perhaps because they have better living conditions than their relatives living in other

317 developing regions in China. ${ }^{36}$ Our previous study found adolescents with migrant parents had better child and adolescent behaviour than and similar self-esteem as those with native born parents. ${ }^{37}$ Furthermore, in Hong Kong, young adults with migrant parents are more upwardly mobile than those with native born parents, as indicated by their greater intergenerational educational mobility, ${ }^{38}$ which has been associated with lower adult adiposity in the West. ${ }^{39}$

Maternal attitudes about body weight may also play a role. Mothers as the main caregivers may affect their child's BMI more than fathers via attitudes and practice of a healthy diet and lifestyle. ${ }^{40}$ Hong Kong women generally perceive slimness as ideal, a social norm which has been evident since the 1970s. ${ }^{41}$ More educated women had lower BMI in Hong Kong in the mid-1990s, ${ }^{42}$ whereas an inverse association was observed in Mainland China about a decade later. ${ }^{43}$ Differences in the association for relative household income could perhaps be explained by the different social patterning of BMI by mother's migrant status.

Associations for relative household income were not independent of parental education in adolescents of native born mothers, but were not relevant in adolescents of migrant mothers. Parental education may be more precisely measured than household income, but it is unclear why it only makes a difference for native born mothers. Parental education may be less predictive of household income for families with migrant mothers because education from Mainland China may not be equally as well accepted as that from Hong Kong. ${ }^{44}$ Alternatively, parental education may be a more salient reflection of living conditions, encompassing 
material resources, child lifestyle, health literacy, cultural competence or intergenerational experiences. ${ }^{18,45}$ More educated Chinese parents seemed to have better family cohesion and parent-child relationship, independent of family income, ${ }^{46}$ and closer family bonds could buffer psychological distress. ${ }^{47}$ Our previous study showed an inverse association of education with child BMI in children with native born mothers while a positive association in children with migrant mothers,${ }^{48}$ consistent with our results on income. Parental education could be another key driver of child BMI, independent of relative income or social rank, among adolescents of native born mothers, whereas education and relative income may represent different attributes of living conditions among adolescents of migrant mothers. As such, effective interventions for child and adolescent adiposity require context-specific consideration of the interplay between migrant background and societal factors. In this study, relative income, but not absolute income, was relevant to adolescent adiposity, with adolescents from more deprived families and/or with migrant mothers more prone to adiposity regardless of parental education. This highlights that addressing relative income by reducing income inequality and promoting intragenerational relative income mobility could contribute to mitigating adolescent adiposity, but changes in socio-cultural norms concerning adiposity are required for adolescents born to migrant mothers in Hong Kong as adiposity may be viewed as desirable in these families.

\section{CONCLUSION}

Relative household income was associated with adolescent BMI z-score and overweight (including obesity), independent of absolute household income, but the direction varied by mother's migrant status, highlighting the interplay between migrant background and sociocultural factors when considering the health impact of relative income (mediated by social comparison with others) in an economically developed society with ethnically homogeneous migrant population. Disentangling the relative importance of specific aspects of 
364 socioeconomic position, and how these factors may interact would help inform effective 365 interventions for tackling the adolescent obesity epidemic.

366

367 
369 Funding: This work is a sub-study of the "Children of 1997" birth cohort which was initially supported by the Health Care and Promotion Fund, Health and Welfare Bureau, Government

371 of the Hong Kong SAR [HCPF Grant \# 216106] and re-established in 2005 funded by the

372 Health and Health Services Research Fund [HHSRF Grant \# 03040771]. This sub-study was

373 funded by the Research Fund for the Control of Infectious Diseases [RFCID Grant \#

374 04050172] and the Health and Health Services Research Fund [HHSRF Grants \# 07080751

375 and \# 08090761], Government of the Hong Kong SAR. The authors reported no financial

376 interests related to this research.

377

378 The authors thank colleagues at the Student Health Service and Family Health Service of the 379 Department of Health for their assistance and collaboration. They thank Dr. Connie Hui for 380 her assistance with the record linkage and the late Dr. Connie $\mathrm{O}$ for coordinating the project 381 and all the fieldwork for the initial study in 1997-8. Dr. MK Kwok thanks the Takemi 382 Program in International Health at the Harvard T.H. Chan School of Public Health for her 383 fellowship during which this manuscript was prepared.

385 Conflict of interest: none declared. 


\section{REFERNCES}

1. Department of Health Public Health Research Consortium, Law C, Power C, Graham $\mathrm{H}$, Merrick D. Obesity and health inequalities. Obesity reviews : an official journal of the International Association for the Study of Obesity 2007; 8 Suppl 1: 19-22.

2. Sobal J, Stunkard AJ. Socioeconomic status and obesity: a review of the literature. Psychological bulletin 1989; 105(2): 260-75.

3. Dinsa GD, Goryakin Y, Fumagalli E, Suhrcke M. Obesity and socioeconomic status in developing countries: a systematic review. Obesity reviews : an official journal of the International Association for the Study of Obesity 2012; 13(11): 1067-79.

4. Wang Y. Cross-national comparison of childhood obesity: the epidemic and the relationship between obesity and socioeconomic status. International journal of epidemiology 2001; 30(5): 1129-36.

5. Due P, Damsgaard MT, Rasmussen M, Holstein BE, Wardle J, Merlo J et al. Socioeconomic position, macroeconomic environment and overweight among adolescents in 35 countries. International journal of obesity 2009; 33(10): 1084-93.

6. Shrewsbury V, Wardle J. Socioeconomic status and adiposity in childhood: a systematic review of cross-sectional studies 1990-2005. Obesity 2008; 16(2): 275-84.

7. Wang Y, Zhang Q. Are American children and adolescents of low socioeconomic status at increased risk of obesity? Changes in the association between overweight and family income between 1971 and 2002. The American journal of clinical nutrition 2006; 84(4): 707-16.

8. Van Hook J, Balistreri KS. Immigrant generation, socioeconomic status, and economic development of countries of origin: a longitudinal study of body mass index among children. Social science \& medicine 2007; 65(5): 976-89.

9. Harling G, Subramanian SV, Barnighausen T, Kawachi I. Income inequality and sexually transmitted in the United States: who bears the burden? Social science \& medicine 2014; 102: 174-82.

10. Putnam JJ, Allshouse JE. Food Expenditures and Income. In: Food Consumption, Prices, and Expenditures, 1970-97. Economic Research Service/United States Department of Agriculture (USDA): US, 1999.

11. Drewnowski A. Obesity, diets, and social inequalities. Nutrition reviews 2009; 67 Suppl 1: S36-9.

12. Li X, Gauthier AH, Strohschein L. Why are some children left out? Factors barring Canadian children from participating in extracurricular activities. Canadian Studies in Population 2009; 36(3-4): 325-345.

13. Perry CD, Kenney GM. Preventive care for children in low-income families: how well do Medicaid and state children's health insurance programs do? Pediatrics 2007; 120(6): e1393-401. 
14. Runciman WG. Relative deprivation and social justice: a study of attitudes to social inequality in twentieth-century, University of California Press: England, 1966.

15. Wood AM, Boyce CJ, Moore SC, Brown GD. An evolutionary based social rank explanation of why low income predicts mental distress: a 17 year cohort study of 30,000 people. J Affect Disord. 2012; 136(3): 882-8.

16. Hamer M, Steptoe A. Cortisol responses to mental stress and incident hypertension in healthy men and women. J Clin Endocrinol Metab. 2012; 97(1): E29-34.

17. Gundersen C, Mahatmya D, Garasky S, Lohman B. Linking psychosocial stressors and childhood obesity. Obesity reviews : an official journal of the International Association for the Study of Obesity 2011; 12(5): e54-63.

18. Kawachi I, Adler NE, Dow WH. Money, schooling, and health: Mechanisms and causal evidence. Ann N Y Acad Sci. 2010; 1186: 56-68.

19. Tsang S. A modern history of Hong Kong, I.B. Tauris: London; New York, 2003.

20. Schooling CM, Hui LL, Ho LM, Lam TH, Leung GM. Cohort profile: 'Children of 1997': a Hong Kong Chinese birth cohort. Int J Epidemiol. 2012; 41(3): 611-20.

21. Organization for Economic Co-operation and Development (OECD) Project on Income Distribution and Poverty. Income Distribution Database (IDD): Gini, poverty, income, Methods and Concepts-What are equivalence scales? 2012 [Jan 15, 2018]. Available from: http://www.oecd.org/social/income-distribution-database.htm [Under Methods and Concepts section] or http://www.oecd.org/els/soc/OECD-NoteEquivalenceScales.pdf.

22. Kwok MK, Subramanian SV, Leung GM, Schooling CM. Household income and adolescent blood pressure in a Chinese birth cohort: "Children of 1997". Social science \& medicine 2015; 144: 88-95.

23. Yitzhaki S. Relative deprivation and the Gini coefficient. The Quaterly Journal of Economics 1979; 93(2): 321-324.

24. Brown GDA, Gardner J, Oswald AJ, Qian J. Does wage rank affect employees' wellbeing? IZA Discussion paper series, No.1505 2005.

25. World Health Organization (WHO). WHO growth reference 5-19 years. WHO: Geneva, 2007.

26. Cole TJ, Bellizzi MC, Flegal KM, Dietz WH. Establishing a standard definition for child overweight and obesity worldwide: international survey. Bmj 2000; 320(7244): 1240-3.

27. Sun X, Briel M, Walter SD, Guyatt GH. Is a subgroup effect believable? Updating criteria to evaluate the credibility of subgroup analyses. BMJ 2010; 340: 850-854.

28. Seaman SR, White IR, Copas AJ, Li L. Combining multiple imputation and inverseprobability weighting. Biometrics 2012; 68(1): 129-37.

29. Schafer JL. Multiple imputation: a primer. Stat Methods Med Res 1999; 8(3-15). 
30. Moons KG, Donders RA, Stijnen T, Harrell FE, Jr. Using the outcome for imputation of missing predictor values was preferred. J Clin Epidemiol 2006; 59(10): 1092-101.

31. Powell LM, Wada R, Krauss RC, Wang Y. Ethnic disparities in adolescent body mass index in the United States: the role of parental socioeconomic status and economic contextual factors. Social science \& medicine 2012; 75(3): 469-76.

32. Oliver LN, Hayes MV. Effects of neighbourhood income on reported body mass index: an eight year longitudinal study of Canadian children. BMC public health 2008; 8: 16.

33. Rossen LM. Neighbourhood economic deprivation explains racial/ethnic disparities in overweight and obesity among children and adolescents in the U.S.A. Journal of epidemiology and community health 2014; 68(2): 123-9.

34. Currie C, Molcho M, Boyce W, Holstein B, Torsheim T, Richter M. Researching health inequalities in adolescents: the development of the Health Behaviour in SchoolAged Children (HBSC) family affluence scale. Social science \& medicine 2008; 66(6): 1429-36.

35. Lam KC, Liu PW. Earnings divergence of Immigrants. Journal of Labor Economics 2002; 20(1): 86-104.

36. Cheung NW. Social stress, locality of social ties and mental well-being: the case of rural migrant adolescents in urban China. Health \& place 2014; 27: 142-54.

37. Leung CY, Leung GM, Schooling CM. Migrant status and child and adolescent psychological well-being: evidence from Hong Kong's 'Children of 1997' birth cohort. Journal of epidemiology and community health 2015; 69(2): 156-61.

38. Lam KC, Liu PW. Intergenerational Educational Mobility in Hong Kong: Are Immigrants More Mobile Than Natives? : Institute of Global Economics and Finance of The Chinese University of Hong Kong; 2015 [May 31, 2017]. Available from: http://www.igef.cuhk.edu.hk/igef_media/workingpaper/IGEF/igef_working_paper_no_42_eng.pdf.

39. Albrecht SS, Gordon-Larsen P. Socioeconomic gradients in body mass index (BMI) in US immigrants during the transition to adulthood: examining the roles of parental education and intergenerational educational mobility. Journal of epidemiology and community health 2014; 68(9): 842-8.

40. Beydoun MA, Wang Y. Parent-child dietary intake resemblance in the United States: evidence from a large representative survey. Social science \& medicine 2009; 68(12): 2137-44.

41. Lee S. Fat, fatigue and the feminine: the changing cultural experience of women in Hong Kong. Culture, medicine and psychiatry 1999; 23(1): 51-73.

42. Woo J, Leung SS, Ho SC, Sham A, Lam TH, Janus ED. Influence of educational level and marital status on dietary intake, obesity and other cardiovascular risk factors in a Hong Kong Chinese population. European journal of clinical nutrition 1999; 53(6): 461-7. 
43. Jones-Smith JC, Gordon-Larsen P, Siddiqi A, Popkin BM. Emerging disparities in overweight by educational attainment in Chinese adults (1989-2006). International journal of obesity 2012; 36(6): 866-75.

44. Lam KC, Liu PW. Relative returns to skills and assimilation of immigrants in Hong Kong. Pacific Economic Review 2002; 7(2): 229-243.

45. Egerter S, Braveman P, Sadegh-Nobari T, Grossman-Kahn R, Dekker M. Exploring the social determinants of health: Education and health. Robert Wood Johnson Foundation Comission to Build a Healthir America: United States, 2011.

46. Zhang X. The effects of parental education and family income on mother-child relationships, father-child relationships, and family environments in the People's Republic of China. Fam Process 2012; 51(4): 483-97.

47. Willgerodt MA. Family and peer influences on adjustment among Chinese, Filipino, and White youth. Nurs Res 2008; 57(6): 395-405.

48. Schooling CM, Yau C, Cowling BJ, Lam TH, Leung GM. Socio-economic disparities of childhood body mass index in a newly developed population: evidence from Hong Kong's 'Children of 1997' birth cohort. Archives of disease in childhood 2010; 95(6): 437-43. 
Table 1. Baseline Characteristics by Absolute Household Income, Relative Household Income Deprivation and Relative Household Income Rank for 5,613 Adolescents From Hong Kong's "Children of 1997” Birth Cohort

\begin{tabular}{|c|c|c|c|c|c|c|c|c|}
\hline \multirow[b]{2}{*}{ Characteristics } & \multirow[b]{2}{*}{ No. } & \multirow[b]{2}{*}{$\%$} & \multicolumn{2}{|c|}{$\begin{array}{l}\text { Absolute } \\
\text { household } \\
\text { income } \\
(\text { HKD) })^{\mathrm{a}}\end{array}$} & \multicolumn{2}{|c|}{$\begin{array}{c}\text { Relative } \\
\text { household } \\
\text { income deprivation } \\
(\mathrm{HKD})^{\mathrm{a}}\end{array}$} & \multicolumn{2}{|c|}{$\begin{array}{c}\text { Relative } \\
\text { household } \\
\text { income rank } \\
\text { (percentile) }^{\mathrm{a}}\end{array}$} \\
\hline & & & Mean & SD & Mean & SD & Mean & SD \\
\hline \multicolumn{9}{|l|}{ Child's sex } \\
\hline Girl & 2,710 & 48.3 & 12,017 & 21,158 & 4,834 & 2,426 & 0.50 & 0.29 \\
\hline Boy & 2,903 & 51.7 & 11,651 & 12,085 & 4,846 & 2,407 & 0.50 & 0.29 \\
\hline \multicolumn{9}{|l|}{ Mother's age at birth (years) } \\
\hline$\leq 24$ & 608 & 11.0 & 7,260 & 4,122 & 6,115 & 1,912 & 0.35 & 0.23 \\
\hline $25-29$ & 1,712 & 31.0 & 10,339 & 8,269 & 5,061 & 2,282 & 0.47 & 0.27 \\
\hline $30-34$ & 2,187 & 39.7 & 13,480 & 12,738 & 4,299 & 2,424 & 0.56 & 0.29 \\
\hline$\geq 35$ & 1,008 & 18.3 & 13,927 & 33,315 & 4,713 & 2,521 & 0.51 & 0.30 \\
\hline \multicolumn{9}{|l|}{ Father's age at birth (years) } \\
\hline$\leq 24$ & 176 & 3.2 & 8,314 & 12,169 & 6,069 & 2,072 & 0.35 & 0.25 \\
\hline $25-29$ & 746 & 13.5 & 10,184 & 6,870 & 5,041 & 2,279 & 0.48 & 0.27 \\
\hline $30-34$ & 1,926 & 34.9 & 13,229 & 11,636 & 4,246 & 2,283 & 0.57 & 0.27 \\
\hline$\geq 35$ & 2,671 & 48.4 & 11,656 & 22,038 & 5,070 & 2,468 & 0.47 & 0.29 \\
\hline \multicolumn{9}{|l|}{ Mother's migrant status } \\
\hline Mainland China or elsewhere & 2,044 & 37.7 & 7,622 & 6,535 & 6,166 & 2,064 & 0.34 & 0.25 \\
\hline Hong Kong & 3,381 & 62.3 & 14,622 & 20,896 & 3,958 & 2,224 & 0.60 & 0.26 \\
\hline \multicolumn{9}{|l|}{ Father's migrant status } \\
\hline Mainland China or elsewhere & 1,607 & 29.5 & 7,896 & 7,567 & 6,120 & 2,122 & 0.34 & 0.25 \\
\hline Hong Kong & 3,849 & 70.6 & 13,394 & 13,695 & 4,258 & 2,317 & 0.57 & 0.27 \\
\hline \multicolumn{9}{|l|}{ Highest parental education } \\
\hline Grade 9 or below & 1,613 & 29.2 & 6,162 & 3,893 & 6,677 & 1,604 & 0.28 & 0.19 \\
\hline Grade $10-11$ & 2,441 & 44.2 & 10,649 & 19,339 & 4,851 & 2,080 & 0.50 & 0.25 \\
\hline Grade 12 or above & 1,468 & 26.6 & 20,274 & 19,003 & 2,696 & 1,882 & 0.75 & 0.22 \\
\hline
\end{tabular}

${ }^{a}$ Absolute or relative household income was based on equalized monthly household income per head in Hong Kong dollar pegged at a rate of 7.8 dollar $=1$ U.S. dollar.

Absolute equivalized household income in Hong Kong dollar (mean \pm SD): $\$ 11,828 \pm 17,078$; relative income deprivation: $\$ 4,840 \pm 2,416$; relative income rank: $0.50 \pm 0.29$. 
Table 2. Unadjusted and Adjusted Association ${ }^{\mathrm{a}}$ of Absolute Household Income ${ }^{\mathrm{b}}$, Relative Household Income Deprivation ${ }^{\mathrm{b}}$ and Relative Household Income Rank ${ }^{\mathrm{b}}$ With Sex- and Age-Standardized Body Mass Index (BMI) z-scores and Overweight (Including Obesity) Status ${ }^{\mathrm{c}}$ at $\sim 13$ Years With $95 \%$ Confidence Intervals (CIs) for 5,613 Adolescents Stratified by Mother's Migrant Status From Hong Kong's "Children of 1997” Birth Cohort using Multiple-Imputation With Inverse Probability Weighting (IPW/MI)

\begin{tabular}{|c|c|c|c|c|c|c|c|c|c|c|c|}
\hline \multirow[b]{3}{*}{ Mother's migrant status } & \multirow[b]{3}{*}{ No. } & \multicolumn{10}{|c|}{ BMI z-score } \\
\hline & & \multicolumn{2}{|l|}{ Model 1} & \multirow{2}{*}{$\begin{array}{c}\text { Model } 2 \\
\beta\end{array}$} & \multicolumn{3}{|c|}{ Model 3} & \multirow{2}{*}{$\begin{array}{c}\text { Model } 4 \\
\beta\end{array}$} & \multicolumn{3}{|c|}{ Model 5} \\
\hline & & & $95 \% \mathrm{CI}$ & & $95 \% \mathrm{CI}$ & $\beta$ & $95 \% \mathrm{CI}$ & & $95 \% \mathrm{CI}$ & $\beta$ & $95 \% \mathrm{CI}$ \\
\hline \multicolumn{12}{|l|}{ Native born mothers } \\
\hline $\begin{array}{l}\text { Absolute household income } \\
\text { (per HKD 1,000 or USD 128) }\end{array}$ & 3,452 & -0.001 & $-0.003,0.001$ & 0.0001 & $-0.002,0.002$ & 0.0001 & $-0.002,0.002$ & 0.00009 & $-0.002,0.002$ & 0.00006 & $-0.002,0.002$ \\
\hline $\begin{array}{l}\text { Relative household income deprivation } \\
\text { (per HKD } 1,000 \text { or USD 128) }\end{array}$ & 3,452 & $\mathbf{0 . 0 3}$ & $0.01,0.04$ & 0.03 & $0.01,0.05$ & NA & & 0.01 & $-0.01,0.04$ & NA & \\
\hline Relative household income rank & 3,452 & -0.22 & $-0.38,-0.06$ & NA & & -0.22 & $-0.40,-0.05$ & NA & & -0.12 & $-0.34,0.10$ \\
\hline \multicolumn{12}{|l|}{ Migrant mothers } \\
\hline $\begin{array}{l}\text { Absolute household income } \\
\text { (per HKD 1,000 or USD 128) }\end{array}$ & 2,161 & 0.01 & $-0.0002,0.02$ & -0.005 & $-0.02,0.01$ & -0.004 & $-0.02,0.01$ & -0.005 & $-0.02,0.01$ & -0.004 & $-0.02,0.01$ \\
\hline $\begin{array}{l}\text { Relative household income deprivation } \\
\text { (per HKD } 1,000 \text { or USD 128) }\end{array}$ & 2,161 & -0.04 & $-0.06,-0.01$ & -0.05 & $-0.09,-0.01$ & NA & & -0.06 & $-0.10,-0.01$ & NA & \\
\hline Relative household income rank & 2,161 & 0.32 & $0.10,0.53$ & NA & & 0.40 & $0.06,0.75$ & NA & & 0.44 & $0.07,0.81$ \\
\hline
\end{tabular}




\begin{tabular}{|c|c|c|c|c|c|c|c|c|c|c|c|}
\hline \multirow[b]{3}{*}{ Mother's migrant status } & \multirow[b]{3}{*}{ No. } & \multicolumn{10}{|c|}{ Overweight (including obesity) } \\
\hline & & \multicolumn{2}{|l|}{ Model 1} & \multicolumn{2}{|l|}{ Model 2} & \multicolumn{2}{|l|}{ Model 3} & \multicolumn{2}{|l|}{ Model 4} & \multirow{2}{*}{$\begin{array}{c}\text { Model } 5 \\
\text { OR }\end{array}$} & \multirow[b]{2}{*}{$95 \% \mathrm{CI}$} \\
\hline & & OR & $95 \% \mathrm{CI}$ & $\mathrm{OR}$ & $95 \% \mathrm{CI}$ & OR & $95 \% \mathrm{CI}$ & OR & $95 \% \mathrm{CI}$ & & \\
\hline \multicolumn{12}{|l|}{ Native born mothers } \\
\hline $\begin{array}{l}\text { Absolute household income } \\
\text { (per HKD 1,000 or USD 128) }\end{array}$ & 3,452 & 0.98 & $0.97,0.99$ & 0.99 & $0.98,1.00$ & 0.99 & $0.98,1.00$ & 0.99 & $0.98,1.00$ & 0.99 & $0.98,1.00$ \\
\hline \multicolumn{12}{|c|}{ Relative household income deprivation } \\
\hline Relative household income rank & 3,452 & 0.46 & $0.35,0.61$ & NA & & 0.57 & $0.37,0.86$ & NA & & 0.73 & $0.46,1.16$ \\
\hline \multicolumn{12}{|l|}{ Migrant mothers } \\
\hline $\begin{array}{l}\text { Absolute household income } \\
\text { (per HKD 1,000 or USD 128) }\end{array}$ & 2,161 & 1.00 & $0.99,1.02$ & 1.00 & $0.97,1.02$ & 1.00 & $0.97,1.02$ & 1.00 & $0.98,1.02$ & 1.00 & $0.98,1.02$ \\
\hline $\begin{array}{l}\text { Relative household income depri } \\
\text { (per HKD 1,000 or USD 128) }\end{array}$ & 2,161 & 0.98 & $0.94,1.03$ & 0.98 & $0.91,1.05$ & NA & & 0.96 & $0.89,1.03$ & NA & \\
\hline Relative household income rank & 2,161 & 1.17 & $0.81,1.68$ & NA & & 1.25 & $0.68,2.29$ & NA & & 1.44 & $0.77,2.70$ \\
\hline
\end{tabular}

Bold indicates statistical significance; Abbreviation: CI, confidence interval; OR, odds ratio.

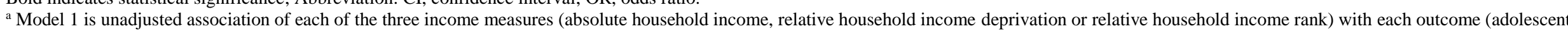
BMI z-score or overweight (including obesity) status);

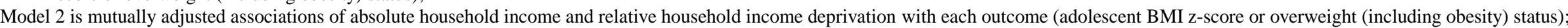

Model 3 is mutually adjusted associations of absolute household income and relative household income rank with each outcome (adolescent BMI z-score or overweight (including obesity) status);

Model 4 is Model 2 additionally adjusted for mother's and father's age, father's migrant status, and highest parental education;

Model 5 is Model 3 additionally adjusted for mother's and father's age, father's migrant status, and highest parental education.

${ }^{\mathrm{b}}$ For native born mothers, absolute equivalized household income in Hong Kong dollar (mean+SD): $\$ 14,622+20,896$; relative income deprivation: $\$ 3,958+2,224$; relative income rank: $0.60+0.26$.

For migrant mothers, absolute equivalized household income in Hong Kong dollar (mean+SD): \$7,622+6,535; relative income deprivation: $\$ 6,166+2,064$; relative income rank: $0.34+0.25$.

${ }^{c}$ Mean difference in z-score: 1 unit change in body mass index z-score is approximated to $2.7 \mathrm{~kg} / \mathrm{m}^{2}$ at 13 years.

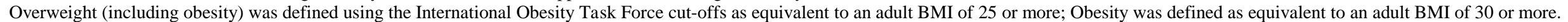


Appendix Table 1. Unadjusted and Adjusted Association ${ }^{\mathrm{a}}$ of Absolute Household Income ${ }^{\mathrm{b}}$, Relative Household Income Deprivation ${ }^{\mathrm{b}}$ and Relative Household Income Rank ${ }^{\mathrm{b}}$ With Sex- and Age-Standardized Body Mass Index (BMI) z-scores and Overweight (Including Obesity) Status ${ }^{\mathrm{c}}$ at $\sim 13$ Years With $95 \%$ Confidence Intervals (CIs) for 5,613 Adolescents Stratified by Mother's Migrant status From Hong Kong's "Children of 1997” Birth Cohort Using Available Case Analysis

\begin{tabular}{|c|c|c|c|c|c|c|c|c|c|c|c|c|c|c|c|}
\hline \multirow[b]{3}{*}{ Mother's migrant status } & \multicolumn{15}{|c|}{ BMI z-score } \\
\hline & \multicolumn{2}{|l|}{ Model 1} & \multicolumn{3}{|c|}{ Model 2} & \multicolumn{3}{|c|}{ Model 3} & \multicolumn{3}{|c|}{ Model 4} & \multicolumn{3}{|c|}{ Model 5} & \multirow[b]{2}{*}{$95 \% \mathrm{CI}$} \\
\hline & No. & $\beta$ & $95 \% \mathrm{CI}$ & No. & $\beta$ & $95 \% \mathrm{CI}$ & No. & $\beta$ & $95 \% \mathrm{CI}$ & No. & $\beta$ & $95 \% \mathrm{CI}$ & No. & $\beta$ & \\
\hline \multicolumn{16}{|l|}{$\underline{\text { Native born mothers }}$} \\
\hline $\begin{array}{l}\text { Absolute household income } \\
\text { (per HKD 1,000 or USD 128) }\end{array}$ & 3,381 & -0.001 & $-0.003,0.001$ & 3,381 & 0.0001 & $-0.002,0.002$ & 3,381 & 0.00006 & $-0.002,0.002$ & 3,326 & -0.0002 & $-0.004,0.003$ & 3,326 & -0.0003 & $-0.004,0.003$ \\
\hline \multicolumn{16}{|c|}{ Relative household income deprivation } \\
\hline (per HKD 1,000 or USD 128) & 3,381 & 0.03 & $0.01,0.05$ & 3,381 & $\mathbf{0 . 0 3}$ & $0.01,0.05$ & & NA & & 3,326 & 0.01 & $-0.01,0.04$ & & NA & \\
\hline Relative household income rank & 3,381 & -0.22 & $-0.38,-0.06$ & & NA & & 3,381 & -0.23 & $-0.40,-0.05$ & & NA & & 3,326 & -0.12 & $-0.36,0.12$ \\
\hline \multicolumn{16}{|l|}{ Migrant mothers } \\
\hline $\begin{array}{l}\text { Absolute household income } \\
\text { (per HKD } 1,000 \text { or USD 128) }\end{array}$ & 2,044 & 0.01 & $-0.001,0.01$ & 2,044 & -0.01 & $-0.02,0.01$ & 2,044 & -0.01 & $-0.02,0.01$ & 1,991 & -0.002 & $-0.02,0.01$ & 1,895 & -0.002 & $-0.02,0.01$ \\
\hline \multicolumn{16}{|c|}{ Relative household income deprivation } \\
\hline (per HKD 1,000 or USD 128) & 2,044 & -0.04 & $-0.06,-0.01$ & 2,044 & -0.05 & $-0.09,-0.01$ & & NA & & 1,991 & -0.04 & $-0.09,0.002$ & 1,895 & NA & \\
\hline Relative household income rank & 2,044 & $\mathbf{0 . 3 0}$ & $0.08,0.51$ & & NA & & 2,044 & 0.40 & $0.05,0.75$ & & NA & & & 0.37 & $-0.01,0.76$ \\
\hline
\end{tabular}

(To be continued) 


\begin{tabular}{|c|c|c|c|c|c|c|c|c|c|c|c|c|c|c|c|}
\hline \multirow[b]{3}{*}{ Mother's migrant status } & \multicolumn{15}{|c|}{ Overweight (including obesity) } \\
\hline & \multirow{2}{*}{$\begin{array}{l}\text { Model } 1 \\
\text { No. }\end{array}$} & \multirow[b]{2}{*}{ OR } & \multicolumn{3}{|c|}{ Model 2} & \multicolumn{3}{|c|}{ Model 3} & \multicolumn{3}{|c|}{ Model 4} & \multicolumn{3}{|c|}{ Model 5} & \multirow[b]{2}{*}{$95 \% \mathrm{CI}$} \\
\hline & & & $95 \% \mathrm{CI}$ & No. & OR & $95 \% \mathrm{CI}$ & No. & OR & $95 \% \mathrm{CI}$ & No. & OR & $\begin{array}{c}95 \% \\
\mathrm{CI}\end{array}$ & No. & $\begin{array}{l}\mathrm{O} \\
\mathrm{R}\end{array}$ & \\
\hline $\begin{array}{l}\text { Absolute household income } \\
\text { (per HKD 1,000 or USD 128) }\end{array}$ & 3,381 & 0.98 & $0.97,0.99$ & 3,232 & 0.99 & $0.98,1.01$ & 3,232 & 0.99 & $0.98,1.01$ & 3,326 & 0.99 & $0.98,1.01$ & 3,326 & 0.99 & $0.98,1.01$ \\
\hline $\begin{array}{l}\text { Relative household income depri } \\
\text { (per HKD } 1,000 \text { or USD 128) }\end{array}$ & 3,381 & 1.09 & $1.05,1.14$ & 3,232 & 1.06 & $1.00,1.13$ & & NA & & 3,326 & 1.03 & $0.96,1.10$ & & NA & \\
\hline Relative household income rank & 3,381 & 0.47 & $0.34,0.64$ & & NA & & 3,232 & 0.59 & $0.36,0.97$ & & NA & & 3,326 & 0.76 & $0.44,1.33$ \\
\hline \multicolumn{16}{|l|}{ Migrant mothers } \\
\hline $\begin{array}{l}\text { Absolute household income } \\
\text { (per HKD 1,000 or USD 128) }\end{array}$ & 2,044 & 1.00 & $0.99,1.02$ & 2,044 & 1.00 & $0.97,1.03$ & 2,044 & 0.99 & $0.97,1.02$ & 1,991 & 1.00 & $0.97,1.03$ & 1,991 & 1.00 & $0.97,1.03$ \\
\hline $\begin{array}{l}\text { Relative household income depri } \\
\text { (per HKD } 1,000 \text { or USD 128) }\end{array}$ & 2,044 & 0.99 & $0.94,1.04$ & 2,044 & 0.98 & $0.90,1.06$ & & NA & & 1,991 & 0.97 & $0.89,1.06$ & 1,991 & NA & \\
\hline Relative household income rank & 2,044 & 1.15 & $0.75,1.75$ & & NA & & 2,044 & 1.28 & $0.62,2.61$ & & NA & & & 1.37 & $0.65,2.89$ \\
\hline
\end{tabular}

Bold indicates statistical significance; Abbreviation: CI, confidence interval; OR, odds ratio.

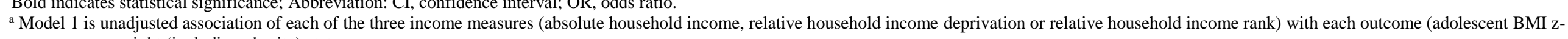
score or overweight (including obesity) status;

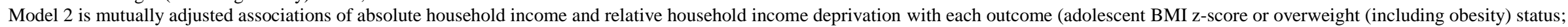

Model 3 is mutually adjusted associations of absolute household income and relative household income rank with each outcome (adolescent BMI z-score or overweight (including obesity) status;

Model 4 is Model 2 additionally adjusted for mother's and father's age, father's migrant status, and highest parental education;

Model 5 is Model 3 additionally adjusted for mother's and father's age, father's migrant status, and highest parental education.

${ }^{b}$ For native born mothers, absolute equivalized household income in Hong Kong dollar (mean+SD): $\$ 14,622+20,896$; relative income deprivation: $\$ 3,958+2,224$; relative income rank: $0.60+0.26$.

For migrant mothers, absolute equivalized household income in Hong Kong dollar (mean+SD): $\$ 7,622+6,535$; relative income deprivation: $\$ 6,166+2,064$; relative income rank: $0.34+0.25$.

${ }^{c}$ Mean difference in z-score: 1 unit change in body mass index z-score is approximated to $2.7 \mathrm{~kg} / \mathrm{m}^{2}$ at 13 years.

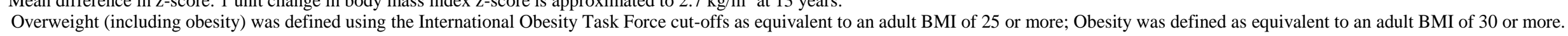


Appendix Table 2. Unadjusted or Adjusted Association ${ }^{\mathrm{a}}$ of Relative Household Income Deprivation and Relative Household Income Rank Defined by

Neighbourhood of Residence, Mother's or Father's Migrant status and Parental Education With Sex- and Age-Standardized Body Mass Index (BMI) Z-scores ${ }^{\mathrm{b}}$ at

13 Years With 95\% Confidence Intervals (CIs) for 5,613 Adolescents Stratified by Mother's Migrant status From Hong Kong's "Children of 1997” Birth Cohort Using Multiple-Imputation With Inverse Probability Weighting (IPW/MI)

\begin{tabular}{|c|c|c|c|c|c|c|c|}
\hline \multirow[b]{2}{*}{ Mother's migrant status } & \multicolumn{3}{|c|}{ Model 1} & \multicolumn{2}{|l|}{ Model 2} & \multicolumn{2}{|c|}{ Model 3} \\
\hline & No. & $\beta$ & $95 \% \mathrm{CI}$ & $\beta$ & $95 \% \mathrm{CI}$ & $\beta$ & $95 \% \mathrm{CI}$ \\
\hline \multicolumn{8}{|l|}{$\underline{\text { Native born mothers }}$} \\
\hline \multicolumn{8}{|c|}{$\begin{array}{l}\text { Relative household income deprivation } \\
\text { (per HKD 1,000 or USD 128) }\end{array}$} \\
\hline Neighbourhood of residence & 3,334 & 0.01 & $0.00005,0.02$ & 0.01 & $-0.0005,0.02$ & 0.01 & $-0.003,0.02$ \\
\hline Mother's migrant status & 3,381 & 0.02 & $0.01,0.03$ & 0.02 & $0.01,0.04$ & 0.01 & $-0.01,0.03$ \\
\hline Father's migrant status & 3,376 & 0.02 & $0.01,0.04$ & 0.02 & $0.004,0.04$ & 0.01 & $-0.01,0.04$ \\
\hline Highest parental education & 3,417 & -0.003 & $-0.02,0.01$ & -0.003 & $-0.02,0.01$ & 0.01 & $-0.01,0.03$ \\
\hline \multicolumn{8}{|l|}{ Relative household income rank } \\
\hline Neighbourhood of residence & 3,334 & -0.20 & $-0.35,-0.05$ & -0.20 & $-0.37,-0.04$ & -0.11 & $-0.31,0.08$ \\
\hline Mother's migrant status & 3,381 & -0.20 & $-0.34,-0.05$ & -0.22 & $-0.39,-0.05$ & -0.11 & $-0.33,0.10$ \\
\hline Father's migrant status & 3,376 & -0.23 & $-0.39,-0.08$ & -0.25 & $-0.44,-0.05$ & -0.13 & $-0.36,0.11$ \\
\hline Highest parental education & 3,417 & -0.07 & $-0.22,0.09$ & -0.06 & $-0.23,0.10$ & -0.10 & $-0.27,0.08$ \\
\hline
\end{tabular}

\title{
Migrant mothers
}

Relative household income deprivation

(per HKD 1,000 or USD 128)

Neighbourhood of residence

Mother's migrant status

2,073

2,044

$-0.003$

$\mathbf{- 0 . 0 6}$

$-0.02,0.01$

$-0.10,-0.02$

$-0.01$

$-0.06$

$-0.02,0.01$

$-0.12,-0.003$

$2,080 \quad-0.01$

$-0.03,0.01$

0.003

$-0.02,0.03$

$-0.01$

$\mathbf{- 0 . 0 7}$

$-0.03,0.01$

$-0.04$

$-0.01$

Highest parental education

(2,

$0.02,0.01$

$\begin{array}{ll}2,073 & \mathbf{0 . 2 3} \\ 2,044 & \mathbf{0 . 2 8} \\ 2,080 & \mathbf{0 . 2 1} \\ 2,105 & \mathbf{0 . 3 3}\end{array}$

Neighbourhood of residence

Mother's migrant status

Father's migrant status

2,105

0.23
0.28
0.21

\begin{abstract}
$0.03,0.44$
\end{abstract}
$0.10,0.47$

0.21

$-0.07,0.49$

$0.05,0.56$

0.22

0.31

$0.02,0.41$

0.16

$-0.10,0.43$

0.32

$0.06,0.53$

0.36

$-0.13,-0.005$

$-0.09,0.002$

$-0.05,0.03$

Bold indicates statistical significance; Abbreviation: CI, confidence interval.

${ }^{a}$ Model 1 is unadjusted association of each of the four relative household income deprivation defined by neighbourhood of residence, mother's or father's migrant status and parental education,

or each of the four relative household income rank defined by neighbourhood of residence, mother's or father's migrant status and parental education, with adolescent BMI z-score;

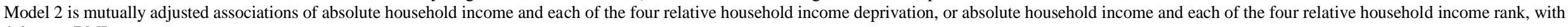
adolescent BMI z-score:

adolescent BMI z-score;
Model 3 is Model 2 additionally adjusted for mother's age, father's age, mother's migrant status (if appropriate), father's migrant status (if appropriate), and highest parental education (if appropriate).
${ }^{b}$ Mean difference in z-score: 1 unit change in body mass index z-score is approximated to $2.7 \mathrm{~kg} / \mathrm{m}^{2}$ at 13 years. 